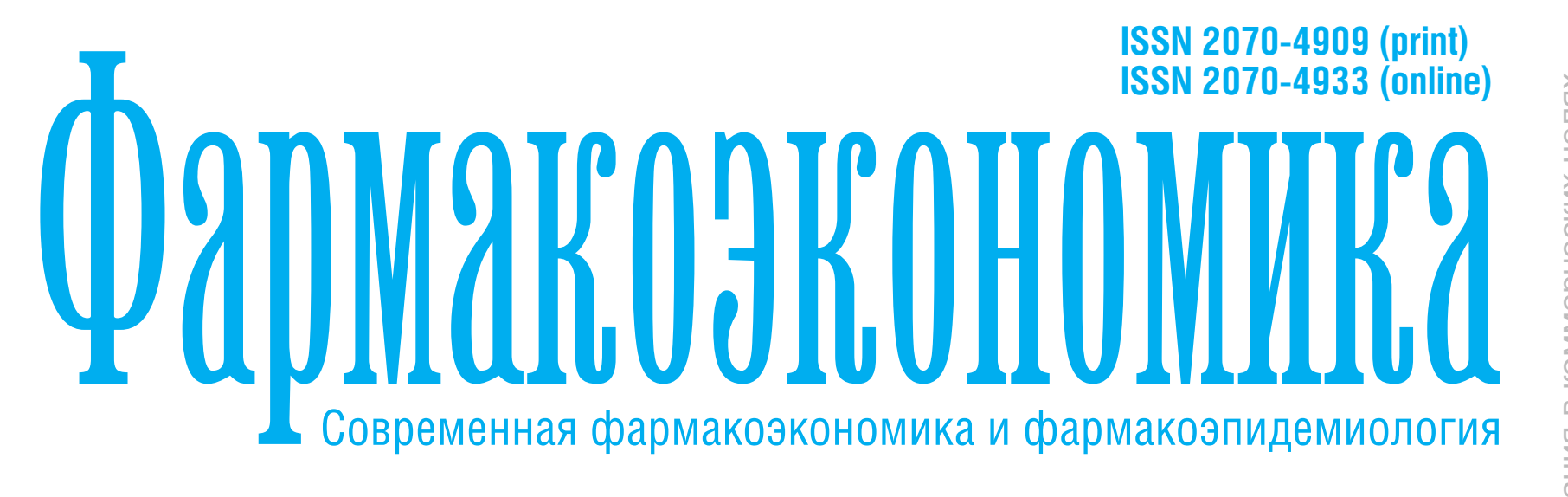

ISSN 2070-4909 (print)

ISSN 2070-4933 (online)



\title{
FARMAKOEKONOMIKA
}

Modern Pharmacoeconomics and Pharmacoepidemiology 


\title{
Анализ приобретения и месячной стоимости антигипертензивной терапии современными фиксированными комбинациями в регионах Дальневосточного федерального округа
}

\author{
Соболева М.С. ${ }^{1}$, Лоскутова Е.Е. ${ }^{2}$ \\ ${ }^{1}$ Федеральное государственное бюджетное образовательное учреждение высшего образования \\ «Дальневосточный государственный медицинский университет» Министерства здравоохранения Российской Федерации \\ (ул. Муравьева-Амурского, д. 35, Хабаровск 680000, Россия) \\ ${ }^{2}$ Федеральное государственное автономное образовательное учреждение высшего образования \\ «Российский университет дружбы народов» (ул. Миклухо-Маклая, д. 8к2, Москва 117198, Россия) \\ Дия контактов: Соболева Мария Сергеевна, e-mail: martimser@mail.ru
}

\begin{abstract}
РЕЗЮMЕ
Цель: анализ приобретения и месячных затрат пациентов на современные фриксированные антигипертензивные комбинации в трех регионах Дальневосточного фредерального округа.

Материал и методы. Проведен внутригрупповой анализ розничной реализации антигипертензивных лекарственных препаратов за 2019 г. в аптечных организациях Хабаровского края, Сахалинской области, Амурской области (n=100). Выполнен расчет месячной стоимости терапии, суммарных показателей продаж. Применены дисперсионный анализ, коэффициент корреляции Спирмена, критерий Краскела-Уоллиса.

Результаты. Максимальным спросом среди сочетаний $\boldsymbol{\beta}$-адреноблокаторов в ценовом диапазоне $100-500$ руб. пользуются комбинации: атенолол+хорталидон и бисопролол+амлодипин. В группе комбинаций ингибиторов ангиотензинпревращающего фермента с диуретиками / блокаторами кальциевых каналов наиболее часто приобретались: периндоприл/рамиприл+индапамид/амлодипин, эналаприл+гидрохлоротиазид - в ценовом сегменте 500-1000 руб. Предпочтения при применении сочетаний блокаторов рецепторов ангиотензин+диуретик / антагонист кальция: валсартан+амлодипин с месячной стоимостью терапии 300-500 руб., лозартан+гидрохлоротазид - 100-500 руб., азилсартан+хлорталидон - 500-1000 руб. Самыми востребованными трехкомпонентными препаратами являлись: валсартан+амлодипин+гидрохлоротиазид, периндоприл+амлодипин+индапамид с месячной стоимостью курса терапии свыше 500 руб. Различия в структуре приобретения между регионами статистически достоверны.
\end{abstract}

Заключение. Доля реализации комбинированных антигипертензивных препаратов остается незначительной. Основными критериями выбора внутри международного непатентованного наименования являются ценовая доступность и доверие к конкретному бренду. Наличие достоверной корреляции структуры приобретения с субъектом доказывает влияние региональных предпочтений специалистов при назначении лекарственных средств.

КЛЮЧЕВЫЕ СЛОВА

Артериальная гипертензия, стоимость терапии, фиксированные комбинации, регионы Дальневосточного федерального округа.

Статья поступила: 24.03.2020 г.; в доработанном виде: 12.08.2020 г.; принята к печати: 15.10.2020 г.

\section{Конфликт интересов}

Авторы заявляют об отсутствии необходимости раскрытия конфлликта интересов в отношении данной публикации.

\section{Вклад авторов}

Все авторы сделали эквивалентный вклад в подготовку публикации.

\section{Для цитирования}

Соболева М.С., ЛоскутоваЕ.Е. Анализ приобретения и месячной стоимости антигипертензивной терапии современными фриксированными комбинациями в регионах Дальневосточного федерального округа. ФАРМАКОЭКОНОМИКА. Современная фрармакоэкономика и срармакоэпидемиология. 2021; 14 (1): 41-49. https://doi.org/10.17749/2070-4909/farmakoekonomika.2021.061.

Analysis of acquisition and the monthly cost of antihypertensive therapy with modern fixed-dose combinations in the Far Eastern Federal District

Soboleva M.S. ${ }^{1}$, Loskutova E.E. ${ }^{2}$ 
${ }^{1}$ Far-East State Medical University (35 Muravyev-Amurskiy Str., Khabarovsk 680000, Russia)

2 Peoples' Friendship University of Russia (8k2 Miklukho-Maklay Str., Moscow 117198, Russia)

Corresponding author: Mariya S. Soboleva, e-mail: martimser@mail.ru

\section{SUIMIMIARY}

Objective: analyzing the acquisition and monthly costs for patients on modern fixed-dose antihypertensive combinations in three regions of the Far Eastern Federal District.

Material and methods. Intra-group analysis of retail of antihypertensive drugs for 2019 in drugstores of the Khabarovsk Region, Sakhalin Region, Amur Region ( $n=100$ ) was carried out. The calculation of the monthly cost of therapy was performed and total sales indicators were identified. Statistical analysis: dispersion analysis, Spearman's rank correlation coefficient, Kruskal-Wallis test.

Results. The maximum demand in patients among combinations of $\beta$-blockers in the price range of 100-500 rubles: atenolol+chlortalidone; bisoprolol+amlodipine. In the grope of combinations of angiotensin-converting enzyme inhibitors with diuretics/calcium channel blockers, the most often acquired were: perindopril/ramipril+indapamide/amlodipine, enalapril+hydrochlorothiazide - in the price segment of 500-1000 rubles. Preferences for the use of combinations of angiotensin II receptor blockers+diuretic/calcium channel blockers: valsartan+amlodipine with a monthly cost of therapy of 300-500 rubles; losartan+hydrochlorothiazide $-100-500$ rubles and azilsartan+chlortalidonee $-500-1000$ rubles. The most popular three-component drugs were valsartan+amlodipine+hydrochlorothiazide, perindopril+amlodipine+indapamide with a monthly cost over 500 rubles. Differences in the acquisition structure of fixed-dose antihypertensive combinations between regions were statistically significant.

Conclusion. The share of sales of combined antihypertensive drugs remains insignificant. The main selection criteria within an international nonproprietary name are affordability or trust in a brand. The presence of a reliable correlation of the acquisition structure with the region proves the influence of regional preferences of specialists in drug prescribing.

\section{KEYWORDS}

Arterial hypertension, cost of therapy, fixed-dose combinations, regions of the Far Eastern Federal District.

Received: 24.03.2020; in the revised form: 12.08.2020; accepted: 15.10.2020

\section{Conflict of interests}

The authors declare they have nothing to disclose regarding the conflict of interests with respect to this manuscript.

\section{Authors' contribution}

The authors contributed equally to this article.

\section{For citation}

Soboleva M.S., Loskutova E.E. Analysis of acquisition and the monthly cost of antihypertensive therapy with modern fixed-dose combinations in the Far Eastern Federal District. FARMAKOEKONOMIKA. Sovremennaya farmakoekonomika i farmakoepidemiologiya / FARMAKOEKONOMIKA. Modern Pharmacoeconomics and Pharmacoepidemiology. 2021; 14 (1): $41-49$ (in Russ.). https://doi. org/10.17749/2070-4909/farmakoekonomika.2021.061.

\section{Основные моменты}

\section{Что уже известно об этой теме?}

- Использование фиксированных комбинаций при медикаментозной терапии артериальной гипертензии позволяет сохранить высокую приверженность пациентов к лечению

> Наиболее назначаемыми антигипертензивными препаратами остаются блокаторы ренин-ангиотензин-альдостероновой системы

- Стоимость медикаментозной терапии является одним из факторов выбора конкретного торгового наименования лекарственного препарата

Что нового дает статья?

П Проанализировано реальное применение антигипертензивных препаратов в трех регионах Дальневосточного федерального округа

- Проанализировано приобретение современных фиксированных антигипертензивных комбинаций в различных ценовых сегментах

Доказано наличие статистически значимых отличий в структуре приобретения препаратов между регионами

Как это может повлиять на клиническую практику в обозримом будущем?

> Рост назначения/применения фиксированных антигипертензивных сочетаний в клинической практике

> Адаптация ассортиментной линейки фриксированных сочетаний внутри каждого международного непатентованного наименования в различных ценовых сегментах

Увеличение ассортимента сочетаний антигипертензивных препаратов, а также их наличия в аптечных организациях
Highlights

What is already known about the subject?

The use of fixed-dose combinations in drug therapy of arterial hypertension allows for maintaining high patient compliance to treatment

- Renin-angiotensin-aldosterone system blockers remain the most prescribed antihypertensive drugs

The cost of drug therapy is one of the factors in choosing a specific trade name for a drug

What are the new findings?

Real usage of antihypertensive drugs in three regions of the Far Eastern Federal District was analyzed

- The acquisition of modern fixed antihypertensive combinations in different price segments was analyzed

Statistically significant differences in the structure of drug acquisition between regions were shown

How might it impact the clinical practice in the foreseeable future?

Increase in prescription/usage of fixed-dose antihypertensive combinations in clinical practice

Adaptation of the range of fixed-dose combinations within each international nonproprietary name in different price segments

Increasing the range of combinations of antihypertensive drugs, as well as their availability in drugstores 


\section{BВEДЕНИЕ / INTRODUCTION}

Проблема эфффективности медикаментозной терапии артериальной гипертензии остается актуальной для всего мира. Доступность лекарственных препаратов для пациентов в странах с высоким и низким уровнями дохода, а также затраты государства и страховых компаний на лечение последствий и осложнений заболевания, перспектива улучшения приверженности, контроля артериального давления и снижения стоимости, марковская модель прогнозирования и расчет показателя продолжительности жизни, скорректированной на ее качество (англ. quality-adjusted life-year, QALY), являются основными предметами современных фрармакоэкономических исследований этой нозологии [1-3]. Так, по данным расчета экономической эфффективности полноценного внедрения клинических рекомендаций Американской коллегии кардиологов (American College of Cardiology, ACC) и Американской ассоциации сердца (American Heart Association, AHA) от 2014 г. в практическую медицину США, это позволит сократить ежегодное количество сердечно-сосудистых событий приблизительно на 56 тыс., а смертей от сердечно-сосудистых причин - на 13 тыс., что приведет к общей экономии затрат [4].

По данным обзора литературы, проведенного в США и Индии, во всем мире лишь около 14\% пациентов достигают эфффективного контроля артериального давления. Большинству больных (больше 60\%) требуются два или более лекарственных средств [5]. По оценкам экспертов, три препарата необходимы для достижения контроля артериального давления примерно у 25-33\% пациентов [6]. Несмотря на расширение доказательной базы преимуществ комбинированной терапии, из-за отсутствия фриксированных комбинаций, особенно поликомпонентных, в перечнях, а также системах государственных гарантий и страховой медицины, они не являются препаратами первой линии и, соответственно, назначаются относительно редко [7].
Тем не менее использование сочетанных антигипертензивных препаратов имеет ряд преимуществ в отношении эффективности и приверженности терапии [8]. Так, по данным метаанализа, проведенного в Японии ( $\mathrm{n}=47891)$, пациентам назначали в среднем $2,0 \pm 1,0$ антигипертензивныхпрепарата и 2,4 1,7 таблетки. Приверженность обратно коррелировала с количеством гипотензивных препаратов или таблеток [9]. В исследовании в Германии отказ от терапии в течение 12 мес был менее вероятен у больных, применяющих фриксированные сочетания, хотя стоимость лечения была выше [10]. В США высокая стоимость фиксированных комбинаций компенсировалась сокращением расходов на использование стационарных услуг [11]. Тройная комбинированная терапия в одной таблетке была экономически эфффективнее по сравнению с «бесплатной» комбинированной терапией, при условии высокой приверженности [12]. По данным европейских (Швейцария, Италия, Германия) исследований, применение трехкомпонентных фиксированных сочетаний может быть наиболее эффективным при гипертонической болезни высокого риска, а также экономически целесообразным в зависимости от региональных условий [6]. По результатам расчета коэффиициента дополнительной экономической эффрективности с учетом показателя QALY, интенсивный контроль гипертонии более рентабелен, чем стандартное лечение, в Китае [13] и Саудовской Аравии [14].

Согласно рекомендациям Российского кардиологического общества по лечению артериальной гипертензии 2020 г. большинству пациентов в качестве стартовой терапии рекомендована комбинация препаратов, предпочтительно фриксированная. Наиболее востребованными сочетаниями являются блокаторы ренин-ангиотензин-альдостероновой системы и дигидропиридиновый блокатор медленных кальциевых каналов (антагонист кальция, АК) и/ или диуретик (Д). К рациональным комбинациям также относят дигидропиридиновый АК+ $\beta$-адреноблокатор (БАБ), АК+Д, БАБ+Д [15].

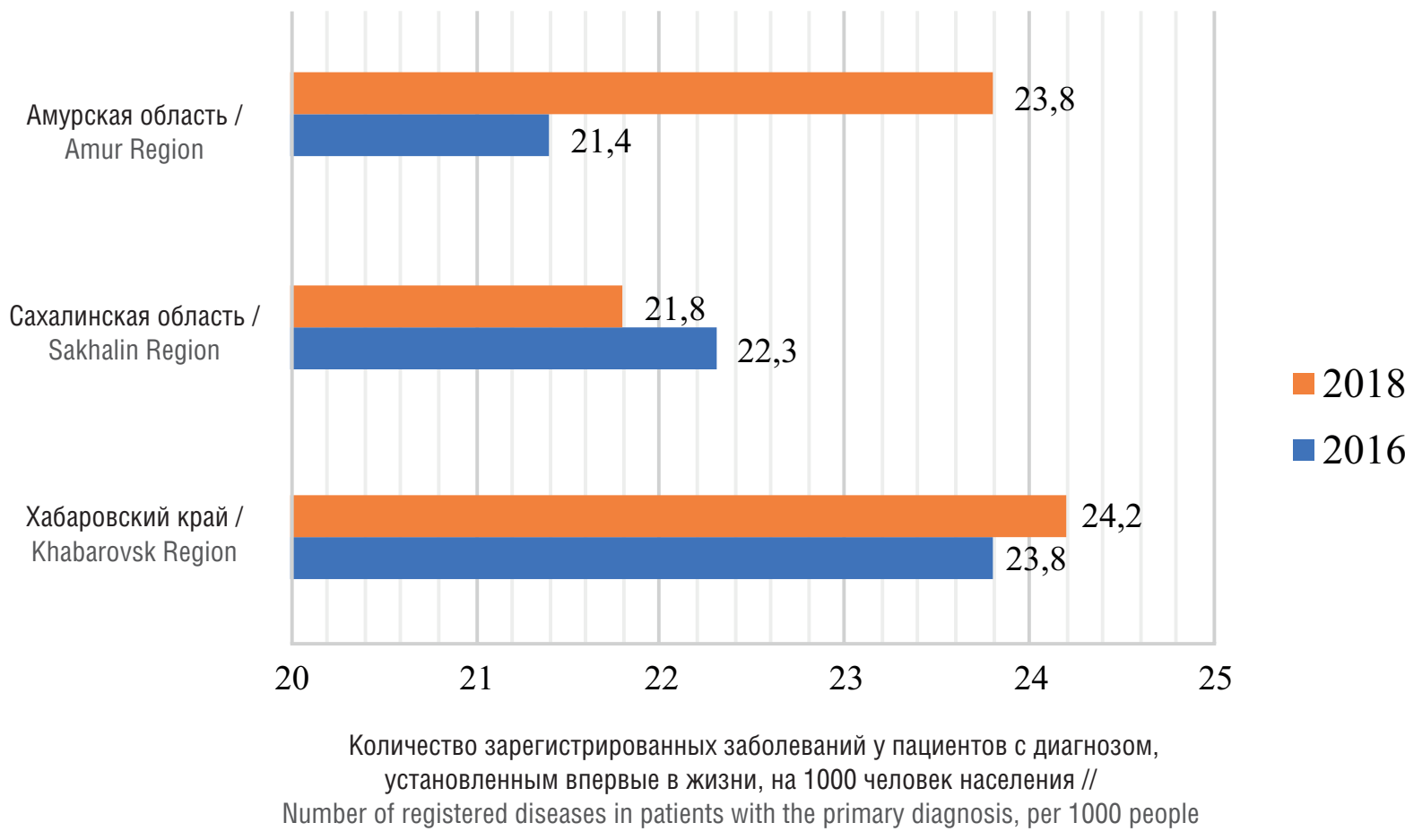

Рисунок 1. Заболеваемость населения болезнями системы кровообращения

Figure 1. Morbidity rate of cardiovascular diseases 


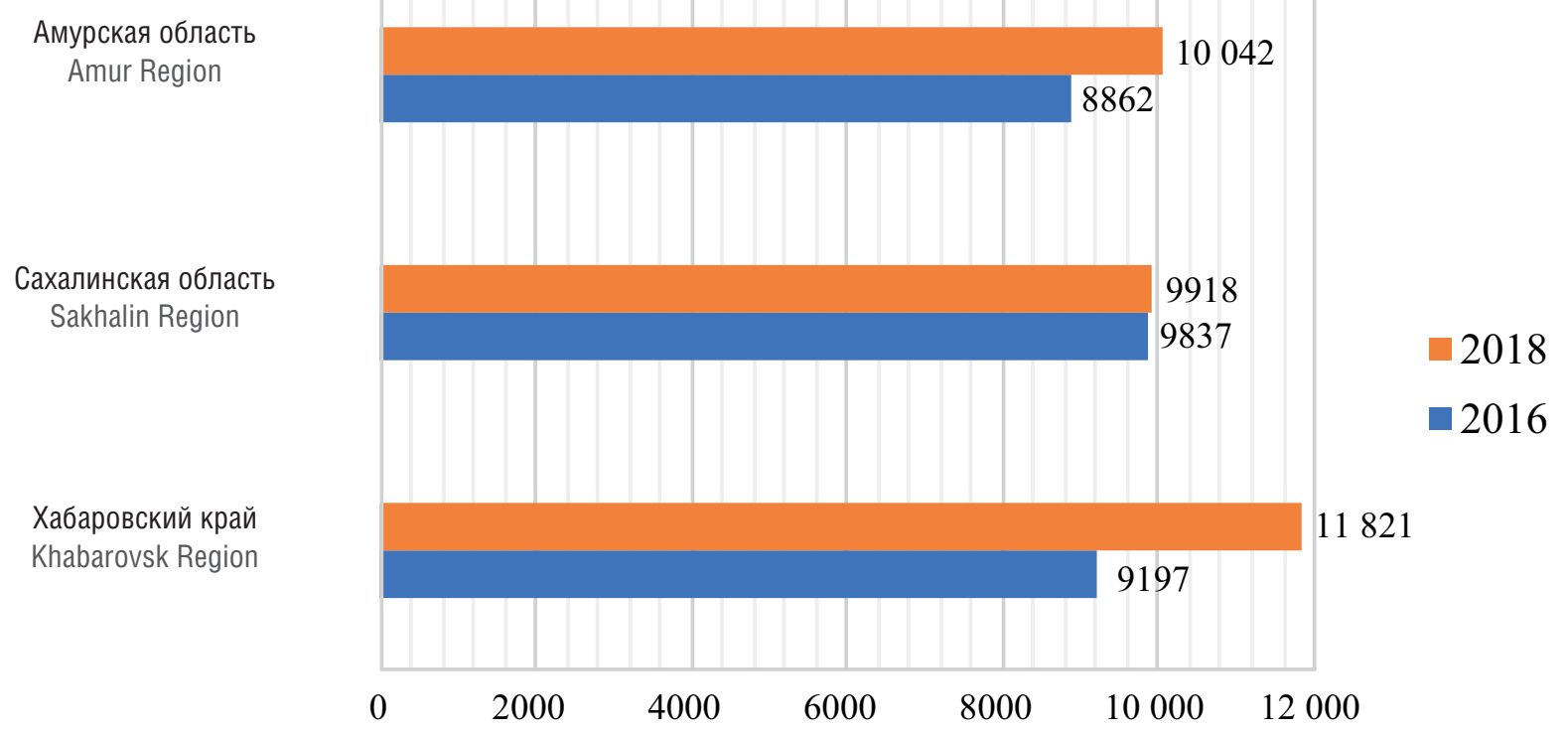

На душу населения, руб. // Per capita, rub.

Рисунок 2. Розничная реализация лекарственных препаратов Figure 2. Pharmaceutical drugs retail sales

Практическое внедрение клинических рекомендаций может быть ограничено необходимостью самостоятельного приобретения пациентами антигипертензивных лекарственных препаратов, а соответственно, и значительным влиянием фактора стоимости на покупку и применение лекарственных препаратов. Кроме того, эффективный контроль артериального давления подразумевает высокую доступность медицинской помощи. Отдаленные регионы с низкой плотностью населения, которые входят в состав Дальневосточного фредерального округа (ДФО), характеризуются концентрацией специализированных медицинских организаций в административных центрах, значительными расстояниями между муниципальными образованиями и высоким уровнем прожиточного минимума. Сложившаяся ситуация может привести к трудностям внедрения рекомендаций и стандартов, перераспределению структуры приобретения препаратов, а также снижению эфффективности и приверженности пациентов к медикаментозной терапии современными антигипертензивными средствами, в частности ффиксированными комбинациями.

В качестве объектов исследования нами были выбраны три географически схожих, соседствующих региона с сопоставимой эпидемиологической ситуацией по заболеваемости артериальной гипертензией (рис. 1), а также суммарному приобретению лекарственных препаратов за 2016-2018 гг. (рис. 2) [16].

Цель - анализ приобретения и месячных затрат пациентов на современные фиксированные антигипертензивные комбинации в трех регионах Дальневосточного федерального округа.

\section{МАТЕРИАЛ И МЕТОДЫ / MATERIAL AND METHODS}

Фармакоэпидемиологическое исследование проводили на основе данных о розничной реализации лекарственных препаратов в 100 аптечных организациях Хабаровского края (ХК), Сахалинской области (СО), Амурской области (АО) за 2019 г. Размер генеральной совокупности аптечных организаций определяли исходя из данных «Справочника организаций России» [17] в исследуе- мых регионах. Выборка аптек составила: 10,3\% в XK ( $\mathrm{n}=65, \mathrm{~N}=629)$ $12,8 \%$ в CO ( $n=25, N=195), 6 \%$ в AO ( $n=10, N=167)$. Таким обра30м, ошибка выборки при 95\% доверительной вероятности и доле признака 50\% составила для ХK 11,5\%, для СО 18\%, для АО 30\%. Это соответствует приближенной и ориентировочной надежности. С 85\% доверительной вероятностью (что допустимо для небольших выборок в социологических исследованиях) этот показатель составил $8,46 \%, 13,5 \%$ и 22\% соответственно, что лежит в интервале обыкновенной и приближенной надежности $[19,20]$.

На основе суммарной розничной реализации выбирали данные продаж антигипертензивных средств по количеству упаковок. Из перечня исключали инъекционные препараты. Затем рассчитывали суммарный показатель реализации антигипертензивных средств, который был взят за 100\%. На следующем этапе определяли долю каждого препарата, суммарную долю международного непатентованного наименования и терапевтического класса. Далее рассчитывали стоимость 30-дневной терапии исходя из количества таблеток в упаковке и принципа определения установленных суточных доз Всемирной организацией здравоохранения [20]. На следующем этапе цену месячного курса терапии кодировали в сегменты: до 100 руб., 100-300 руб., 300-500 руб., 500-1000 руб., 1000-2000 руб., 2000-3000 руб. и свыше 3000 руб. Наконец, данные группировали в ценовые сегменты внутри терапевтического класса.

Для обработки данных использовали программу Office Excel 365 (Microsoft, США).

В рамках данной статьи приводится информация о реализации и стоимости терапии наиболее распространенными фиксированными комбинациями.

\section{Методы статистического анализа}

Для статистического анализа данных применяли программное обеспечение SPSS Statistics 25 (IBM, США) (русскоязычная версия). Использовали дисперсионный анализ, а также коэффрициент корреляции Спирмена, критерий Краскела-Уоллиса. В качестве порогового значения уровня значимости использовали $\alpha=0,05$. 


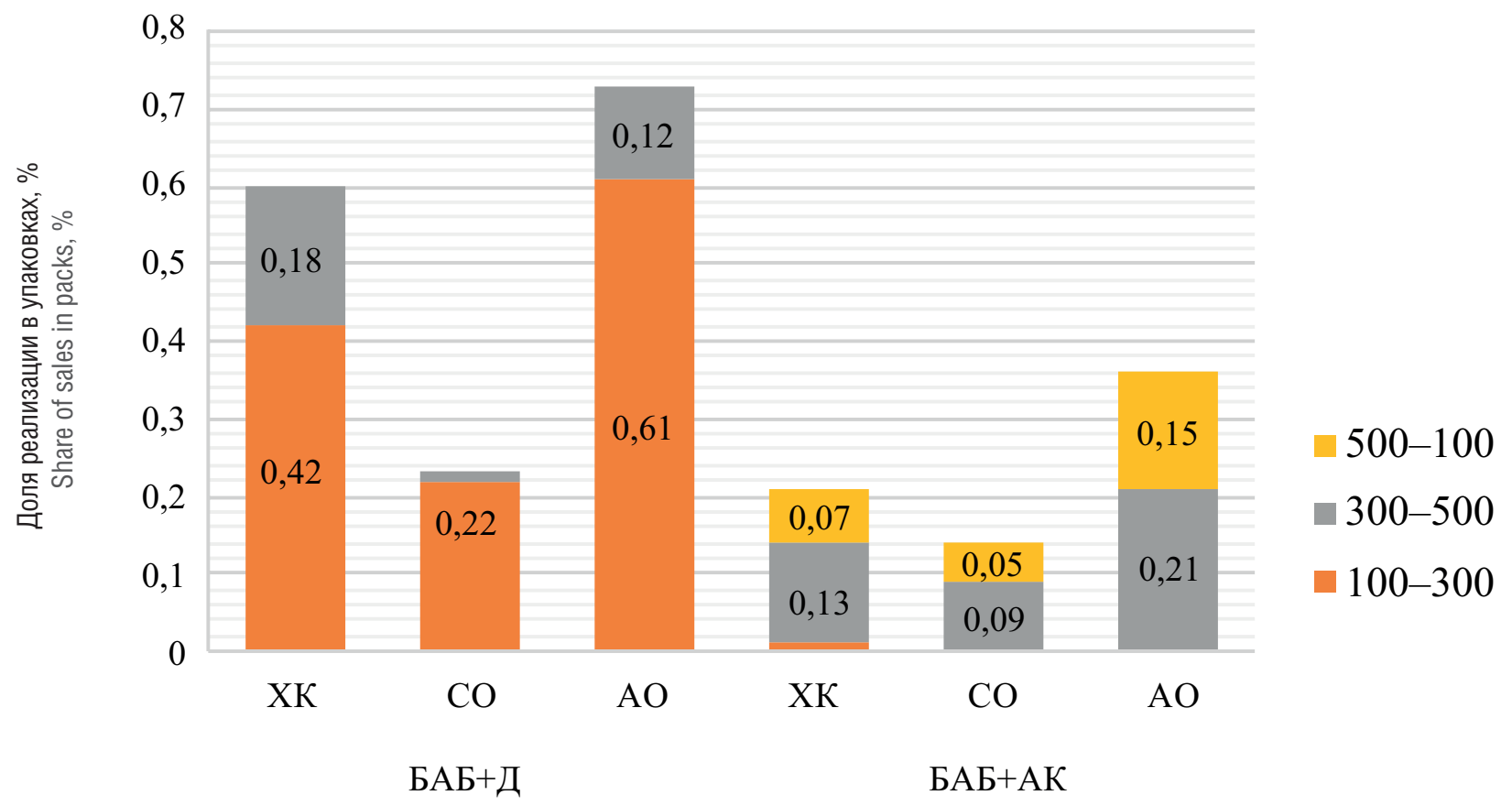

Терапевтический класс/регион // Therapeutic class/region

Рисунок 3. Приобретение и месячная стоимость терапии фиксированных сочетаний $\beta$-адреноблокаторов.

ХK - Хабаровский край; СО - Сахалинская область; АО - Амурская область; БАБ - $\beta$-адреноблокатор; Д-диуретик; АК - блокатор медленных кальциевых каналов Figure 3. Acquisition and monthly cost of therapy with fixed combinations of $\beta$-adrenoblockers.

XK - Khabarovsk Region; CO - Sakhalin Region; AO - Amur Region; БАБ - $\beta$-adrenoblocker; Д-diuretic; AK - slow channel-blocking agent

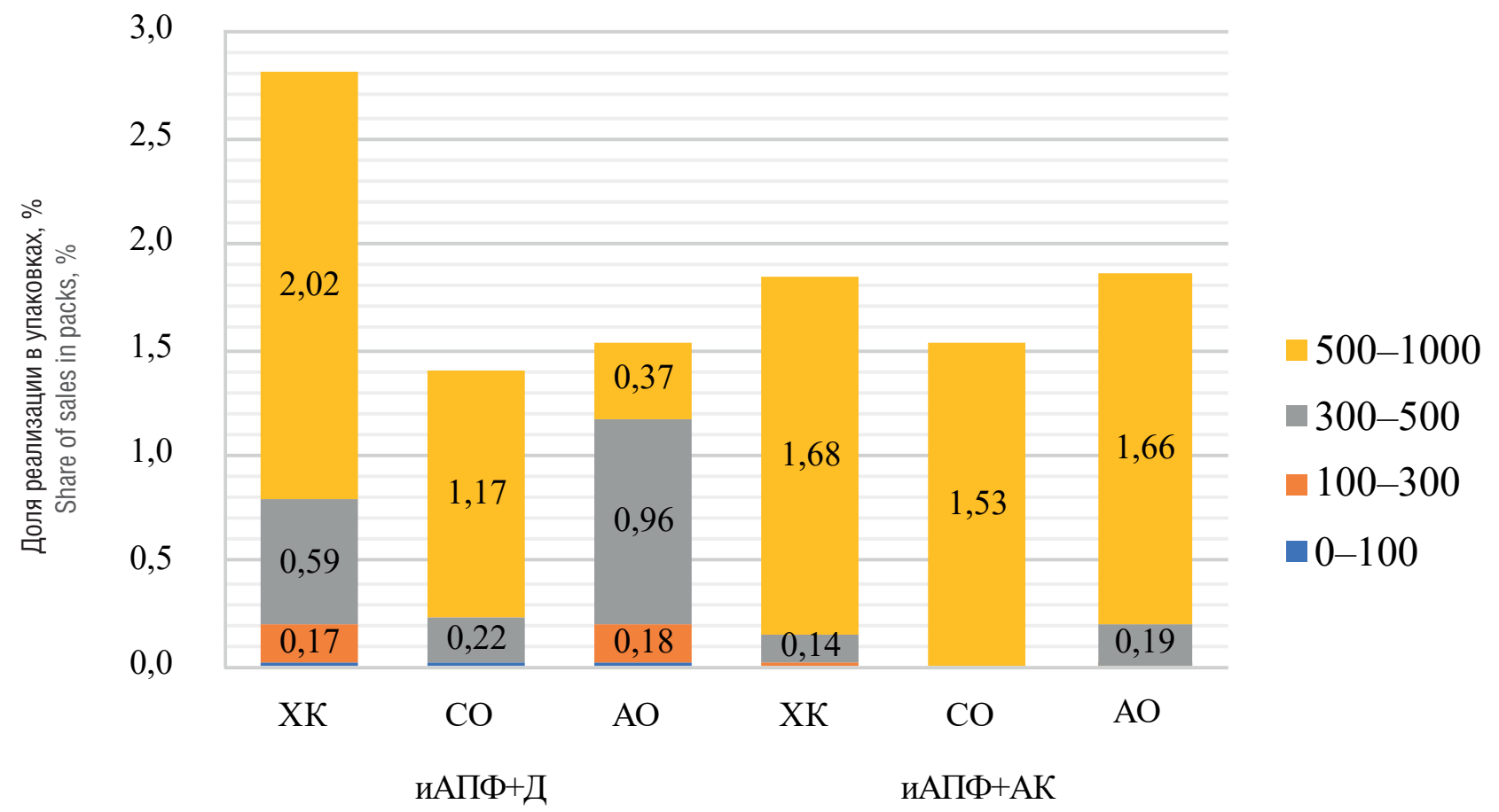

Терапевтический класс/регион // Therapeutic class/region

Рисунок 4. Приобретение и месячная стоимость терапии фриксированных сочетаний иАПФ.

ХК - Хабаровский край; СО - Сахалинская область; АО - Амурская область; иАПФ - ингибитор ангиотензинпревращающего фермента; Д - диуретик; АК - блокатор медленных кальциевых каналов

Figure 4. Acquisition and monthly cost of therapy with fixed-combinations of angiotensin converting enzyme inhibitors.

XK - Khabarovsk Region; CO - Sakhalin Region; AO - Amur Region; иАПФ - angiotensin converting enzyme inhibitor; Д-diuretic; AK - slow channel-blocking agent 


\section{РЕЗУЛЬТАТЫ И ОБСУЖДЕНИЕ / RESULTS AND DISCUSSION}

Приобретение фриксированных комбинаций БАБ с диуретиками (Д)/АК представлено на рисунке 3.

Максимальные показатели приобретения данных комбинированных сочетаний $(0,73 \%)$ наблюдались в А0. Наиболее применяемыми сочетаниями являлись атенолол+хлорталидон (торговое наименование (ТН) «Тенорик» № 28): 0,42\% в XK, 0,21\% в СО и 0,6\% в АО. Популярность данной комбинации можно объяснить ценовой доступностью - до 300 руб. за месяц. Тем не менее низкая селективность сочетаний атенолола по сравнению с зарегистрированными комбинациями бисопролол+гидрохлоротиазид может обусловливать более высокий риск развития побочных эффектов, что в перспективе может привести к удорожанию терапии. Комбинации БАБ+АК характеризовались низким спросом на фармацевтическом рынке исследуемых регионов. Наиболее востребованным у пациентов являлось сочетание бисопролол+амлодипин (ТН «Конкор AM» № 30): 0,19\% в XК, 0,13\% в СО и 0,36\% в АО. Сочетания небиволол+амлодипин и метопролол+срелодипин относительно недавно (в 2018 и 2013 г.) зарегистрированы в Российской Федерации и выведены на фрармацевтический рынок. Поэтому, вероятно, специалисты в отдаленных регионах имеют небольшой опыт их практического применения и данные сочетания пользуются невысоким спросом. Тем не менее в этих терапевтических классах максимальные показатели реализации наблюдаются в низких ценовых сегментах, что доказывает влияние фрактора цены при приобретении сочетаний БАБ.

Наиболее назначаемыми антигипертензивными препаратами являются блокаторы ренин-ангиотензин-альдостероновой системы. Приобретение фиксированных сочетаний иАПФ с АК/Д представлено на рисунке 4. Данные препараты наиболее востребованы в ХK ( $3 \%$ и 1,6\% соответственно). Наибольшие доли реализации во всех регионах приходятся на ценовой сегмент 300-1000 руб. Несмотря на наличие широкой ассортиментной линейки более доступных по цене генерических препаратов, максимальные показатели реализации в 2019 г. были у сочетания периндоприл+индапамид (ТН «Нолипрел A», «Нолипрел А форте», «Нолипрел А би-форте» № 30): 1,72\% в XК и 1,12\% в СО. В АО лидером группы являлось сочетание эналаприл+гидрохлоротиазид (ТН «Энап Н» № 20) с долей реализации $0,44 \%$. Полученные результаты демонстрируют ориентацию на конкретный бренд - оригинальную комбинацию в XK и СО, а также на ценовую доступность в АО и более частое использование сочетания иАПФ+АК в регионе.

Схожая ситуация наблюдается в терапевтическом классе сочетаний иАПФ+АК. Максимальные показатели реализации отмечены у фиксированных комбинаций периндоприл+амлодипин (ТН «Престанс» № 30) - 1,13\% в ХК, рамиприл+амлодипин (ТН «Эгипресс» № 30) - 0,63\% в СО и 1,13\% в А0, несмотря на перерегистрацию препарата в 2019 г. Ориентация на конкретные бренды в данном случае может быть объяснена узким ассортиментом торговых наименований в рамках одного международного непатентованного, а также активной их промоцией на региональных фрармацевтических рынках.

Блокаторы рецепторов ангиотензина (БРА) также являются востребованной терапевтической группой. Ряд преимуществ с точки зрения эффеективности (действие непосредственно на эффекторном органе, а не на этапе метаболизма), а также безопасности (низкий риск развития сухого кашля) способствует росту интереса специалистов и пациентов, а соответственно, и высоким показателям реализации. Приобретение и месячная стоимость терапии фиксированных сочетаний БРА+АК/Д представлена на рисунке 5.

Данные современные сочетания наиболее востребованы в А0, где суммарная доля реализации БРА+Д составляет 10,1\%. Причем наибольшие показатели реализации в нижнем ценовом сегменте 100-300 руб. (5,35\%) также наблюдаются в A0, из них на сочетание лозартан+гидрохлоротиазид (ТН «Лориста Н» № 60) приходилось

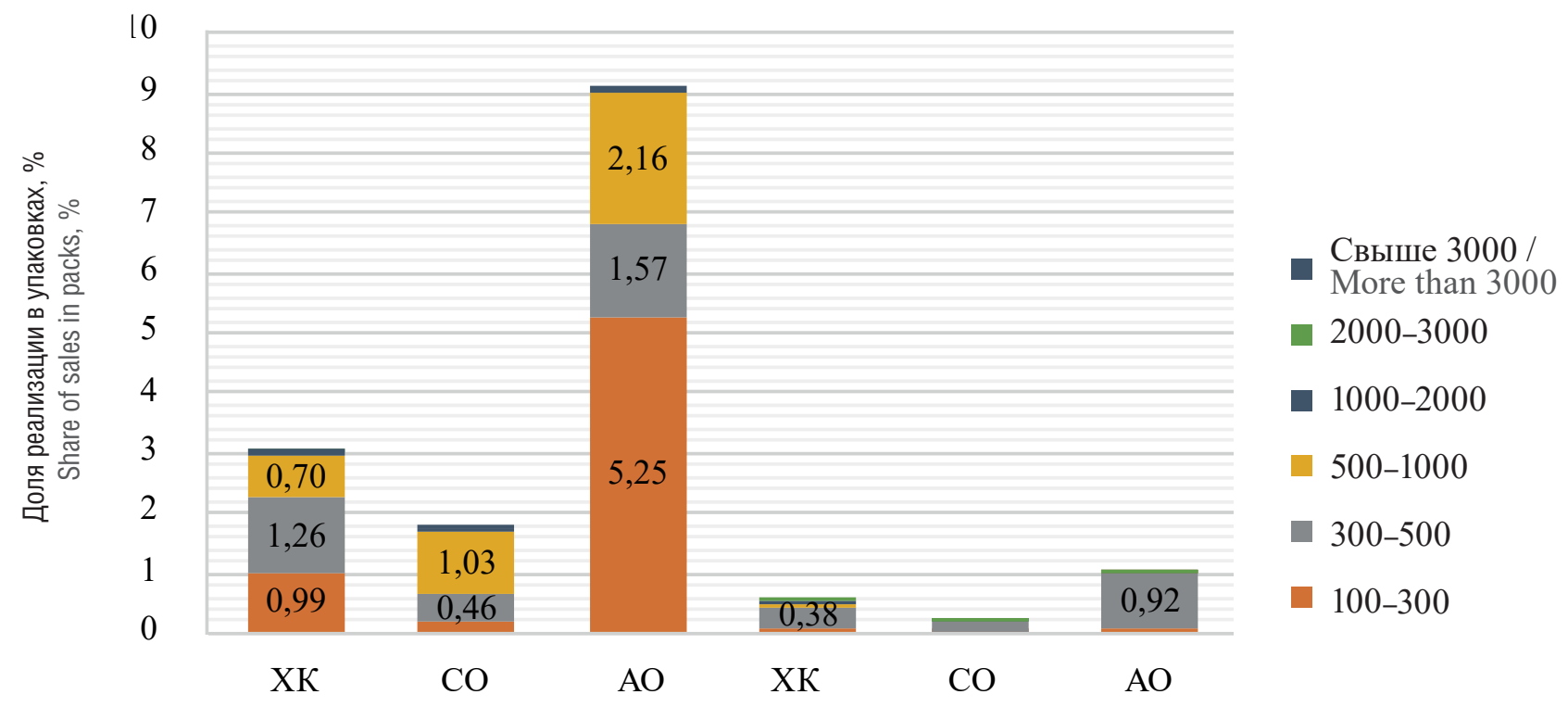

БРА+Д

БРА+АК

Терапевтический класс/регион // Therapeutic class/region

Рисунок 5. Приобретение и месячная стоимость терапии фиксированных сочетаний БРА.

ХK - Хабаровский край; СО - Сахалинская область; АО - Амурская область; БРА - блокатор рецепторов ангиотензина; Д - диуретик; АК - блокатор медленных кальциевых каналов

Figure 5. Acquisition and monthly cost of therapy with fixed combinations of angiotensin receptor blockers.

XK - Khabarovsk Region; CO - Sakhalin Region; A0 - Amur Region; БPA - angiotensin receptor blocker; Д - diuretic; AK - slow channel-blocking agent 


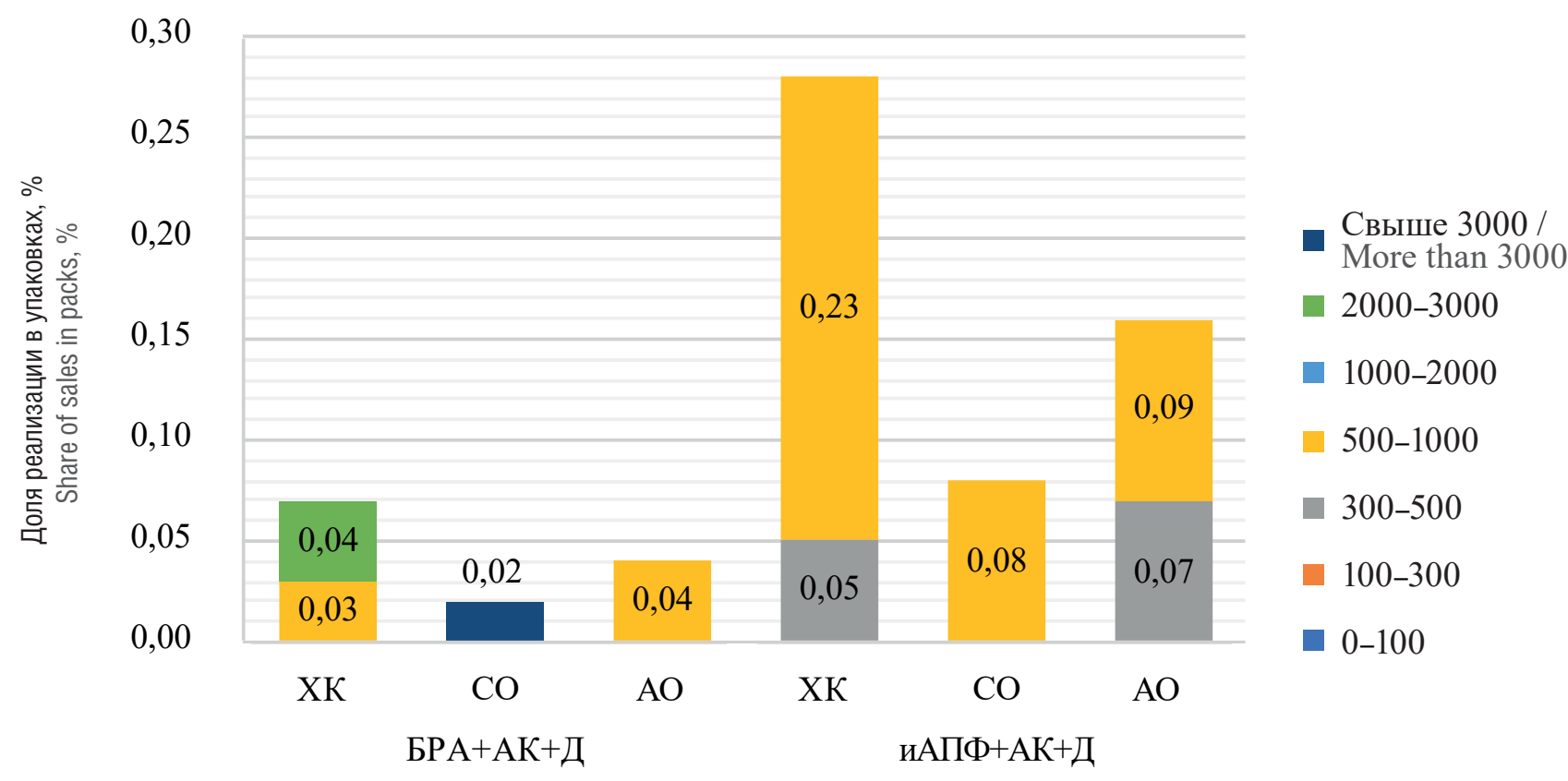

Терапевтический класс/регион // Therapeutic class/region

Рисунок 6. Приобретение и месячная стоимость терапии трехкомпонентными фиксированными сочетаниями.

ХК - Хабаровский край; СО - Сахалинская область; АО - Амурская область; БРА - блокатор рецепторов ангиотензина; Д- диуретик; АК - блокатор медленных кальциевых каналов; иАПФ - ингибитор ангиотензинпревращающего фермента

Figure 6. Acquisition and monthly cost of therapy with three-component fixed combinations.

XK - Khabarovsk Region; CO --Sakhalin Region; A0 - Amur Region; БРА - angiotensin receptor blocker; Д- diuretic; AK - slow channel-blocking agent; иАПФ - ACE inhibitor

3\%. В XK наиболее востребованы препараты в ценовом сегменте 300-500 руб. Лидером группы является сочетание лозартан+гидрохлоротиазид (ТН «Лориста Н» № 30) - 0,72\%. В СО максимальный спрос был на комбинации 500-1000 руб., но лидером группы стал недавно зарегистрированный (2015 г.) препарат азилсартан+хлорталидон (торговое наименование «Эдарби Кло» № 28) - 0,88\%.

В исследуемых регионах спрос на современные сочетания БРА+АК был несущественный с максимумом в ценовом сегменте 300-500 руб. Лидером группы являлось сочетание валсартан+амлодипин (ТН «Вамлосет» № 30): 0,31\% в ХK, 0,16\% в СО и 0,83\% в АО. Выбор пациентов может быть объяснен значительной стоимостью месячного курса терапии оригинальным препаратом (ТН «Экфорж») - более 2000 руб.

Трехкомпонентные комбинации являются перспективными препаратами для медикаментозной терапии артериальной гипертензии. Приобретение этих лекарственных средств в исследуемых регионах приведено на рисунке 6

Несмотря на удобство использования, преимущества комплаенса «полипилюли» не были востребованы в субъектах в 2019 г. Суммарные показатели реализации в натуральном эквиваленте сочетаний иАПФ/БРА+АК+Д составляли менее $0,3 \%$, что еще раз доказывает предпочтение пациентами комбинированной терапии в виде нескольких однокомпонентных препаратов. Максимальный спрос наблюдался в XK. Лидерами группы являлись сочетания валсартан+амлодипин+гидрохлоротиазид (ТН «Ко-Эксрорж» № 28): 0,04\% в XK, 0,02\% в СО, а также ТН «Ко-Вамлосет» № 28: 0,04\% в АО. Сочетание периндоприл+амлодипин+индапамид (ТН «Трипликсам» № 30): 0,17\% в XК, 0,06\% в С0, а также ТН «Ко-Дальнева» № 30: $0,07 \%$ в АО. Полученные результаты аналогичны данным по двухкомпонентным сочетаниям, что доказывает предпочтение исполь- зования брендированных препаратов компании Servier (Франция) в ХК и СО при выборе иАПФ.

На следующем этапе исследования был проведен статистический анализ для оценки достоверности различий в структуре приобретения фриксированных сочетаний в трех регионах. При использовании непараметрического критерия Краскела-Уоллиса для трех независимых выборок $p=0,001$. Далее был применен дисперсионный анализ (одномерная общая линейная модель), $p=0,028$. Взаимосвязь показателей реализации с регионом оценивали с использованием коэффрициента Спирмена - корреляция слабая, но достоверная $\left(r s={ }_{0,03} 0,112_{0,19} ; p=0,005\right)$. Полученные данные доказывают наличие региональных различий при приобретении пациентами фриксированных сочетаний. Это можно объяснить узкой ассортиментной линейкой ТН в рамках международных непатентованных наименований, предпочтениями специалистов и промоцией производителей и дистрибьюторов.

\section{ЗАКЛЮЧЕНИЕ / CONCLUSION}

Несмотря на преимущества фриксированных сочетаний с точки зрения эфффективности и комплаенса (приверженности) терапии, реальное приобретение двух- и трехкомпонентных препаратов в трех исследуемых регионах ДФ0 в структуре реализации антигипертензивныхпрепаратовостаетсянезначительным. Наибольшие суммарные показатели продаж наблюдаются в АО. Самыми приобретаемыми комбинированными препаратами являются: атенолол+ хлорталидон, бисопролол+амлодипин, периндоприл+индапамид, эналаприл+гидрохлоротиазид, периндоприл+амлодипин, рамиприл+амлодипин, лозартан+гидрохлоротиазид, азилсартан+хлорталидон и валсартан+амлодипин. Среди сочетаний 
БАБ+Д, БРА+Д (в АО) наиболее востребованы препараты в ценовом диапазоне месячного курса терапии 100-300 руб.; БАБ+АК, БРА+Д (в ХК), БРА+АК - 300-500 руб.; АПФ+Д/АК, БРА+Д (в СО), иАПФ+АК+Д, БРА+АК+Д (в АО) - 500-1000 руб. Трехкомпонентные комбинации иАПФ+АК+Д востребованы только в ХК и СО.

\section{Ограничения}

Анализ проводился в трех субъектах Дальневосточного фредерального округа. Не учитывалась реализация инъекционных антигипертензивных препаратов.
Наблюдаются достоверные отличия в структуре приобретения комбинированных препаратов между регионами, причиной которых могут быть предпочтения специалистов и пациентов, а также ассортимент торговых наименований, представленный в фрармацевтических организациях.

\section{Restrictions}

The analysis was carried out in three regions of the Far Eastern Federal District. The sales of injectable antihypertensive drugs were not taken into account.

\section{ЛИТЕРАТУРА:}

1. Hazra N.C., Rudisill C., Jackson S.H., Gulliford M.C. Costeffectiveness of antihypertensive therapy in patients older than 80 years: cohort study and Markov model. Value Health. 2019; 22 (12): 1362-9. https://doi.org/10.1016/j.jval.2019.08.001.

2. Gu D., He J., Coxson P.G., et al. The costeffectiveness of low-cost essential antihypertensive medicines for hypertension control in China: a modelling study. PLoS Med. 2015; 12 (8): e1001860. https://doi. org/10.1371/journal.pmed.1001860.

3. González-Gómez S., Meléndez-Gomez M.A., López-Jaramillo P. Fixed-dose combination therapy to improve hypertension treatment and control in Latin America. Arch Cardiol Mex. 2018; 88 (2): 129-35. https://doi.org/10.1016/j.acmx.2017.06.001.

4. Moran A.E., Odden M.C., Thanataveerat A., et al. Cost-effectiveness of hypertension therapy according to 2014 guidelines. N Engl J Med. 2015; 372 (5): 447-55. https://doi.org/10.1056/NEJMsa1406751.

5. Salam A., Huffman M.D., Kanukula R., et al. Two-drug fixed-dose combinations of blood pressure-lowering drugs as WHO essential medicines: an overview of efficacy, safety, and cost. J Clin Hypertens (Greenwich). 2020; 22 (10): 1769-79. https://doi.org/10.1111/ jch.14009.

6. Düsing R., Waeber B., Destro M., et al. Triplecombination therapy in the treatment of hypertension: a review of the evidence. $J$ Hum Hypertens. 2017; 31 (8): 501-10. https://doi.org/10.1038/jhh.2017.5. 7. Laurent S., Bejan-Angoulvant T., Boutouyrie P. Prescription of fixed dose combinations of antihypertensive drugs. Rev Prat. 2019; 69 (10): 1094-8.

8. Mazón P., Galve E., Gómez J., et al. Medical expert consensus in AH on the clinical use of triple fixed-dose antihypertensive therapy in Spain. Hipertens Riesgo Vasc. 2016; 33 (4): 133-44. https://doi. org/10.1016/j.hipert.2016.03.001.

9. Ishida T., Oh A., Hiroi Sh., et al. Treatment patterns and adherence to antihypertensive combination therapies in Japan using a claims database. Hypertens Res. 2019; 42 (2): 249-56. https://doi. org/10.1038/s41440-018-0127-0.

10. Bramlage P., Schmidt S., Sims H. Fixed-dose vs free-dose combinations for the management of hypertension - an analysis of 81 958 patients. J Clin Hypertens (Greenwich). 2018; 20 (4): 705-15. https://doi.org/10.1111/jch.13240.

\section{REFERENCES:}

1. Hazra N.C., Rudisill C., Jackson S.H., Gulliford M.C. Costeffectiveness of antihypertensive therapy in patients older than 80 years: cohort study and Markov model. Value Health. 2019; 22 (12): 1362-9. https://doi.org/10.1016/j.jval.2019.08.001.
11. Deshmukh K.B., Qian J., Garza K.B., et al. Health care costs associated with addition, titration, and switching antihypertensive medications after first-line treatment: results from a commercially insured sample. J Manag Care Spec Pharm. 2017; 23 (6): 691-9. https://doi.org/10.18553/jmcp.2017.23.6.691.

12. Wang X., Chen H., Ej E., et al. Cost-effectiveness analysis of antihypertensive triple combination therapy among patients enrolled in a Medicare advantage plan. Expert Rev Pharmacoecon Outcomes Res. 2020: 1-8. https://doi.org/10.1080/14737167.2020.1800457.

13. Xie X., He T., Kang J., et al. Cost-effectiveness analysis of intensive hypertension control in China. Prev Med. 2018; 111: 110-4. https:// doi.org/10.1016/j.ypmed.2018.02.033.

14. Ziyad A., Yasser A., Adnan A., et al. Cost-effectiveness of more intensive blood pressure treatment in patients with high risk of cardiovascular disease in Saudi Arabia: a modelling study of metaanalysis. Int J Hypertens. 2019; 2019: 6019401. https://doi. org/10.1155/2019/6019401.

15. Клинические рекомендации. Артериальная гипертензия у взрослых. 2020. Российское кардиологическое общество. URL: https://scardio.ru/content/Guidelines/Clinic_rek_AG_2020.pdf (дата обращения 26.03.2021).

16. Здравоохранение в России 2019. Приложение к сборнику (инсормация в разрезе субъектов Российской Федерации). URL: https://rosstat.gov.ru/folder/210/document/13218 (дата обращения 26.03.21).

17. Справочник организаций России. Медицина. Аптеки. URL: https://www.orgpage.ru/rossiya/аптеки/ (дата обращения 26.03.2021)

18. Калькулятор расчета ошибки и размера выборки. FDF group. URL: https://fdfgroup.ru/poleznayainformatsiya/stati/vyborka-tipyvyborok-raschet-oshibki-vyborki/\#1_anchor (дата обращения 26.03.2021).

19. Кошевой О.С., Карпова М.К. Определение объема выборочной совокупности при проведении региональных социологических исследований. Известия высших учебных заведений. Поволжский регион. Общественные науки. 2011; 2 (18): 98-104.

20. ATC/DDD Index. URL: https://www.whocc.no/atc_ddd_ index/?code=C (дата обращения 26.03.2021).

2. Gu D., He J., Coxson P.G., et al. The costeffectiveness of low-cost essential antihypertensive medicines for hypertension control in China: a modelling study. PLoS Med. 2015; 12 (8): e1001860. https://doi. org/10.1371/journal.pmed.1001860. 
3. González-Gómez S., Meléndez-Gomez M.A., López-Jaramillo P. Fixed-dose combination therapy to improve hypertension treatment and control in Latin America. Arch Cardiol Mex. 2018; 88 (2): 129-35. https://doi.org/10.1016/j.acmx.2017.06.001.

4. Moran A.E., Odden M.C., Thanataveerat A., et al. Cost-effectiveness of hypertension therapy according to 2014 guidelines. N Engl J Med. 2015; 372 (5): 447-55. https://doi.org/10.1056/NEJMsa1406751.

5. Salam A., Huffman M.D., Kanukula R., et al. Two-drug fixed-dose combinations of blood pressure-lowering drugs as WHO essential medicines: an overview of efficacy, safety, and cost. J Clin Hypertens (Greenwich). 2020; 22 (10): 1769-79. https://doi.org/10.1111/ jch.14009.

6. Düsing R., Waeber B., Destro M., et al. Triplecombination therapy in the treatment of hypertension: a review of the evidence. $J$ Hum Hypertens. 2017; 31 (8): 501-10. https://doi.org/10.1038/jhh.2017.5. 7. Laurent S., Bejan-Angoulvant T., Boutouyrie P. Prescription of fixed dose combinations of antihypertensive drugs. Rev Prat. 2019; 69 (10): 1094-8.

8. Mazón P., Galve E., Gómez J., et al. Medical expert consensus in AH on the clinical use of triple fixed-dose antihypertensive therapy in Spain. Hipertens Riesgo Vasc. 2016; 33 (4): 133-44. https://doi. org/10.1016/j.hipert.2016.03.001.

9. Ishida T., Oh A., Hiroi Sh., et al. Treatment patterns and adherence to antihypertensive combination therapies in Japan using a claims database. Hypertens Res. 2019; 42 (2): 249-56. https://doi. org/10.1038/s41440-018-0127-0.

10. Bramlage P., Schmidt S., Sims H. Fixed-dose vs free-dose combinations for the management of hypertension - an analysis of 81 958 patients. J Clin Hypertens (Greenwich). 2018; 20 (4): 705-15. https://doi.org/10.1111/jch.13240.

11. Deshmukh K.B., Qian J., Garza K.B., et al. Health care costs associated with addition, titration, and switching antihypertensive medications after first-line treatment: results from a commercially insured sample. J Manag Care Spec Pharm. 2017; 23 (6): 691-9. https://doi.org/10.18553/jmcp.2017.23.6.691.

12. Wang X., Chen H., Ej E., et al. Cost-effectiveness analysis of antihypertensive triple combination therapy among patients enrolled in a Medicare advantage plan. Expert Rev Pharmacoecon Outcomes Res. 2020: 1-8. https://doi.org/10.1080/14737167.2020.1800457.

13. Xie X., He T., Kang J., et al. Cost-effectiveness analysis of intensive hypertension control in China. Prev Med. 2018; 111: 110-4. https:// doi.org/10.1016/j.ypmed.2018.02.033.

14. Ziyad A., Yasser A., Adnan A., et al. Cost-effectiveness of more intensive blood pressure treatment in patients with high risk of cardiovascular disease in Saudi Arabia: a modelling study of metaanalysis. Int J Hypertens. 2019; 2019: 6019401. https://doi. org/10.1155/2019/6019401.

15. Clinical guidelines. Arterial hypertension in adults. 2020. Russian Society of Cardiology. Available at: https://scardio.ru/content/ Guidelines/Clinic_rek_AG_2020.pdf (in Russ.) (accessed 26.03.2021). 16. Healthcare in Russia 2019. Appendix to the collection (information in the context of the subjects of the Russian Federation). Available at: https://rosstat.gov.ru/folder/210/document/13218 (in Russ.) (accessed 26.03.2021).

17. Directory of Russian organizations. Medicine. Pharmacies. Available at: https://www.orgpage.ru/rossiya/аптеки/ (in Russ.) (accessed 26.03.2021).

18. Error and sample size calculator. FDF group. Available at: https:// fdfgroup.ru/poleznayainformatsiya/stati/vyborka-tipy-vyborokraschet-oshibki-vyborki/\#1_anchor (in Russ.) (accessed 26.03.2021). 19. Koshevoy O.S., Karpova M.K. Determination of the volume of sample population during regional sociological research. News of Higher Education Institutions. Volga Region. Social Sciences. 2011; 2 (18): 98-104 (in Russ.).

20. ATC/DDD Index. Available at: https://www.whocc.no/atc_ddd_ index/?code=C (accessed 26.03.2021).

\section{Сведения об авторах}

Соболева Мария Сергеевна - к.б.н., доцент кафедры фармации и фармакологии ФГБОУ ВО «Дальневосточный государственный медицинский университет» Минздрава России. ORCID ID: https://orcid.org/0000-0002-5452-0584; РИНЦ SPIN-код: 6819-5236. E-mail: martimser@mail.ru.

Лоскутова Екатерина Ефимовна - д.фарм.н., профрессор, заведующая кафедрой управления и экономики фармации Медицинского института ФГАОУ В0 «Российский университет дружбы народов». ORCID ID: https://orcid.org/0000-0002-1514-0941; РИНЦ SPIN-код: 1133-0394.

\section{About the authors}

Mariya S. Soboleva - PhD (Biol.), Associate Professor, Chair for Pharmacy and Pharmacology, Far Eastern State Medical University. ORCID ID: https://orcid. org/0000-0002-5452-0584; RSCI SPIN-code: 6819-5236. E-mail: martimser@mail.ru.

Ekaterina E. Loskutova - Dr. Pharm. Sci., Chief of Chair for Organization and Economics of Pharmacy, Medical Institute, Peoples' Friendship University of Russia. ORCID ID: https://orcid.org/0000-0002-1514-0941; RSCI SPIN-code: 1133-0394. 